
SEA CONDITIONS

W. Robert Story, Virginia Tech

Brian LeCroy, Virginia Tech

Christina Pace, Virginia Tech

Michael Palmer, Virginia Tech

Leigh McCue, Virginia Tech 


\title{
Case Studies: Catastrophic Vessel Dynamics in Extreme Sea Conditions
}

\begin{abstract}
Natural disasters have been at the public forefront for the past year, with examples ranging from the Indian Ocean tsunami of December 2004 to a "freak wave" slamming the Norwegian Dawn at sea in April 2005 to Hurricanes Katrina and Rita during the summer of 2005. While the catastrophic human toll has rightly been the main headline, these events have also taken their toll on the maritime industry as house boats are capsized, oil rigs knocked from their moorings, and vessels of all sizes washed ashore. While many of the recent events that led to heavy damage or capsize of a ship were unpreventable, steps can be taken to inform and educate future ship captains and engineers about extreme sea conditions so as to save cargo, ships, and lives. The authors apply knowledge of ship dynamics to case studies of various vessels caught in shipthreatening natural events, such as hurricanes, tsunamis, rogue waves, and inland storms, to develop a formulation of the extent of risk in these environments and recommendations for operators. By surveying prior research as well as recent and historical incidents, the primary objective of this work is to aid in the prevention of exposure to catastrophic vessel conditions. As a secondary objective, the paper discusses the pedagogical benefits of incorporating these types of case studies in an undergraduate curriculum.
\end{abstract}

\subsection{Introduction}

Throughout history, natural disasters have taken their toll on both human lives and the economy. For ships at sea, these disasters loom as a threat to passengers, crew and cargo, as well as to the ships themselves. While the disasters themselves cannot be prevented, measures can be taken to lessen the toll they take on the shipping industry.

In 2004 alone, economic losses attributed to natural disasters exceeded 115 billion dollars, with at least 56 billion of those losses coming from hurricanes striking US mainland, and another estimated 10 billion attributable to the Indian Ocean tsunami. ${ }^{1}$ These losses pale in comparison to the losses in human life, but much can be learned from these events and that knowledge applied to reduce the risk of both human and economic losses. Four of the most destructive natural threats to shipping are hurricanes, rogue waves, inland storms, and tsunamis. Though the first three are much more common occurrences, all four have the potential to cause substantial damage to ships that are exposed to the brunt of their powerful forces.

Hurricanes create some of the most powerful and destructive winds known to the maritime industry. Causing billions of dollars worth of damage and taking lives every year, they are one of the most dangerous aspects of nature. Often unavoidable, these storms usually strike several times a year. The best way of dealing with them is to avoid or minimize contact altogether. With the increasing technology used in weather forecasting, meteorologists are more adequately predicting the paths of these hurricanes, which aids in avoidance. ${ }^{2}$ 
When hurricanes form, converging trade winds from the two hemispheres create an unstable spiraling mass of air. The energy from the warm tropic water fuels these storms as they grow. The spiraling winds lift up evaporated water which creates a low pressure system at the surface. This low pressure enables the storm to pull in more and more vapor, and thus grow. The "eye", or center, is described as extremely calm and peaceful, with blue skies overhead, but completely surrounded by dark storm clouds. The eye can sometimes be up to 25 miles across and ships have even been known to ride out hurricanes in them. ${ }^{2}$

Rogue waves occur more frequently than hurricanes, but until recently no one knew for a fact if rogue waves even existed, much less how they form, where they are most likely to occur, or what properties make up the waves. Before evidence of the subject was established in 1995 when the Draupner oil rig measured a 26 meter wave $^{3}$, rogue or freak waves were thought of as myths or stories told by sailors and were often grouped with sightings of sea monsters and mermaids. Now they are widely accepted and believed to be the leading cause of the sinking of large ships. ${ }^{4}$

A rogue wave is a large wave, much larger than the surrounding swell. Rogue waves are defined as 2.2 times the significant wave height (which is the average height of the highest one third of the waves in a sample). A rogue wave is different than a tsunami in that rogue waves are deepwater waves where tsunamis are shallow-water waves. The difference between the two is not just the depth of the water but the depth in comparison with the wavelength. Also, deep-water waves are wind-generated waves where shallow water waves such as tsunamis are created by seismic activity relatively close to the surface.

While rogue waves pose a threat to deep water shipping, tsunamis mostly affect ships already docked in harbor. The shallow-water waves are initiated by an undersea earthquake or landslide that changes the landscape of the sea floor. Near the epicenter of the earthquake the ground is pushed up, created a swell in the water above it. When the column of water is pushed above the normal sea level, gravity causes it to travel in a horizontal motion, creating the tsunami wave. The speed of the tsunami varies approximately by the formula $\sqrt{g \times h}$, where $g$ is the acceleration of earth's gravity and $h$ is the depth of the water at that location. As the tsunami approaches land, the amplitude of the wave increases as the sea floor rises to the coast due to conservation of mass. ${ }^{5}$ The waves can reach incredible heights, as seen in the Indian Ocean tsunami of December 2004.

While the three natural disasters mentioned above come to the forefront of public recognition, inland storms can be just as devastating as any hurricane strike. In the fall, cold, arid winds are forced down from the Northern part of Canada to meet warmer winds coming up from the Gulf of Mexico. ${ }^{6}$ This brings an onset of storms to the center of the United States. These storms branch out, many of which head to the Great Lakes. Inland storms are particularly devastating because there are waves coming in from each of the surrounding coasts to batter the ship from all sides. 


\subsection{Case Studies}

\subsection{Inland Storms: The Edmund Fitzgerald}

Severe weather has threatened vessels on the Great Lakes for years. For example, during the Great Lakes Storm of 1913, at least 19 ships sank, killing 248 aboard. $^{7}$ In the 1970's, perhaps the most mysterious of Great Lakes shipwrecks occurred, the wreck of the S.S. Edmund Fitzgerald.

When the Edmund Fitzgerald set out for Zug Island on November 9, 1975 there was a gale warning issued by the National Weather Service. Winds were reported at speeds greater than 50 knots, and waves were estimated to be over 10 feet high. ${ }^{8}$ The Fitzgerald continued to move out into the storm, which proved deadly. They were out of sight and off the radar in just minutes. The members of the ship did not send a distress signal, which suggests the storm provided a quick sinking. Four ships were originally sent out to search for the Fitzgerald. One ended up turning back in the middle of the voyage and another took almost 24 hours to get to the scene.

There are many theories on the sinking of the Edmund Fitzgerald. The two most prominent are issues related to the severity of the storm and issues surrounding the maintenance of the boat. ${ }^{8}$ The way that the boat was found split in two, with the sections separated by more than 170 feet, suggests that the boat took on a lot of water quickly and unevenly. ${ }^{9}$ The Edmund Fitzgerald's freeboard had been decreased due to an authorized change to her Plimsoll mark, thus it would be easier to take on water in high seas. ${ }^{8}$

\subsubsection{Prevention}

An accurate weather forecast can be the difference between life and death when traveling. Much of the problem did indeed come from the storm and the poor approximation of its power. The weather report the Fitzgerald received was not always perfect. The report estimated winds to 2842 knots, when in actuality winds were recorded over 70 knots throughout that day. ${ }^{6}$ There were also unexpected shifts in wind direction that caused problems for both ships. When the Anderson, a nearby ship, and Fitzgerald headed for the Canadian shore, they were trying to avoid winds from the Northeast. As they were moving, the winds changed to be coming from the Northwest, keeping both ships from their desired targets. The Fitzgerald sank in 1975, and there has been much improvement in weather services since then.

There has been speculation that much of the Fitzgerald's problems came from leaky hatch covers that were to be repaired during the next shipping season. ${ }^{8}$ It is impossible to prevent routine damage from occurring, but it is relatively simple to keep things in good working condition after yearly inspections. Had the hatch covers been watertight it is possible that water would not have leaked in to the hatches and the Fitzgerald might have been able to stay afloat long enough for a distress signal to be sent, which might have saved lives in the end.

\subsection{Hurricanes and Houseboats}

Houseboat living in the United States became very popular during the 1970's. It represented a way of getting away from the stresses of the modern American lifestyle. However, there has 
been a steady decline in houseboat living. Zoning rights are making it harder to establish dock space, and many environmentalists argue that it has detrimental effects on the environment. In recent years the dangers of houseboat living have also been at the forefront of this decline; severe, larger than usual hurricanes have devastated houseboat communities in the south over the last few years. ${ }^{10}$

Many of the older houseboats, especially the ones dating back to the 70's, have a very box like hull form. Generally the walls of the "house" sit right on top of the hull. These boats, for the most part, are made for calm fresh water use, or extremely protected saltwater areas. They are not very stable because of their relatively high center of gravity and are not meant for use in rough or choppy ocean water. However, even in very well protected bays near the ocean, houseboats are very susceptible to extreme conditions when tropical storms or hurricanes strike.

\subsubsection{Bay Village}

North Bay Village, located just north of Miami in Biscayne Bay, is a small houseboat community. Before Hurricane Wilma struck Florida, 19 houseboats resided in this community. After Wilma, there were only nine still floating. ${ }^{11}$ The small community was completely destroyed; leather couches, TV's, and furniture were all left bobbing in the littered bay. Many residents who had ridden out Hurricane Katrina, earlier perceived as a more severe threat, felt they could easily ride out Hurricane Wilma as well. These residents were forced to evacuate in the early hours of the morning as conditions deteriorated. Wilma was uniquely different from Katrina in that the winds came from the west, which left the boats far more exposed. A track of Wilma is shown in Figure 1 below, showing the storm sweeping across Florida from west to east, unlike most hurricanes. Condos and other superstructures on land had shielded the wind from Katrina, and in a way offered protection to them. During Wilma they were susceptible to the westward winds, reaching speeds of $105 \mathrm{mph}$ at times. ${ }^{12}$

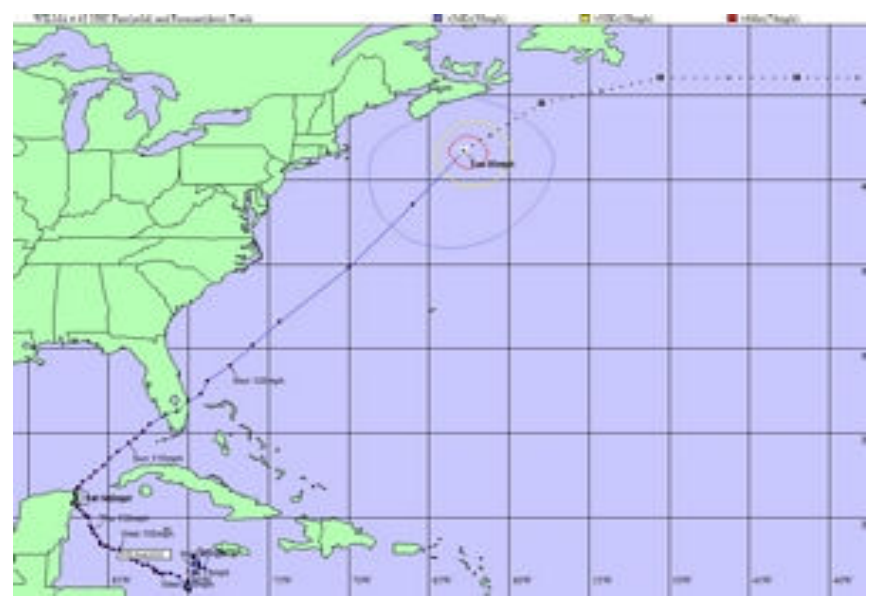

Figure 1: The track of Hurricane Wilma ${ }^{15}$ 
There are two main reasons for the devastation of North Bay Village, both of them reiterating the fact that most houseboats are not designed for ocean use: the poor stability of houseboats with excessively high centers of gravity, and the extreme windage effects on most houseboats.

\subsubsection{Stability}

High centers of gravity can be a contributor to some houseboats poor stability. As mentioned earlier, several older houseboats have hulls that can be closely approximated by box barges. Having superstructures with nearly all of the weight above the waterline creates a very high center of gravity for most of these vessels. The initial stability of a vessel is calculated using the equation $G Z=G M * \sin (\theta)$. GZ is the righting arm for the vessel; when positive it produces a righting moment bringing the vessel back to its upright equilibrium state, and when negative it produces a moment in the opposite direction which causes the vessel to capsize. It is clear that the higher the center of gravity $(\mathrm{KG})$ is, the smaller $\mathrm{GM}$ will be, i.e. a higher KG will make the initial stability of the vessel much smaller. Note that this theory is only valid for small angles of roll, but the principle associated with the location of the center of gravity is consistent for all angles. $^{13}$

Upon surveying houseboat manufacturers in search of approximate values of $\mathrm{KG}$ for their designs, an interesting revelation was made: none of the manufacturers took KG into consideration when designing their vessels. Typical respondents stated that their designs were not meant to operate in rough conditions, normally considered waves over 4-5 feet, which would clearly present a problem on the ocean. North Bay Village, being in a well protected area, never saw seas outside the prescribed region until a hurricane such as Wilma or Katrina or some other strange natural event occurred.

\subsubsection{Windage}

Windage is defined as the part of the vessel exposed to wind, and more specifically the part of the vessel above the water line that is perpendicular to the wind. Windage creates a heeling moment, which is generally represented in terms of a wind heeling arm (WHA). Expressing it in terms of a heeling arm allows it to be plotted on a static stability curve (GZ curve) to find the heel angle. The formula

for WHA is:

$$
\begin{aligned}
\mathrm{WHA}= & \frac{\left(0.0035 \cdot V_{W}^{2} \cdot A \cdot l \cdot \cos ^{2}(\phi)\right)}{2240 \cdot \Delta} \\
& \text { WHA }=\text { Wind heeling arm } \\
& V_{W}=\text { Wind velocity, knots } \\
& A=\text { Perpendicular wind area } \\
& l=\text { vertical distance between CSA and CLR } \\
& \text { CSA }=\text { Centroid of sail area (perpendicular area exposed to wind) } \\
& \text { CLR }=\text { Centroid of Resistance (area below waterline) } \\
& \Delta=\text { displacement, long tones } \\
& \phi=\text { angle of heel }
\end{aligned}
$$


With this simple moment equation, it becomes apparent why houseboats are extremely vulnerable in high wind situations such as hurricanes. Their general above deck shape is a rectangle, exposing the maximum area to the oncoming wind, and thus maximizing the (A) term in the WHA equation. This rectangular shape is also uniform throughout the height of the superstructure, unlike other ocean going vessels where the area decreases as you go further above deck. This means (L), the distance between the CSA and CLR, is far greater for houseboats. When examining the basic WHA equation it also becomes apparent that adding a second floor to a houseboat, as many of those in North Bay Village had, has a detrimental effect. Both the perpendicular wind area and the moment arm are drastically increased, while the draft typical does not change very much.

Windage causes even more problems when a boat is anchored or moored. The wind will cause the boat to both yaw and heel. This puts an extreme amount of unaccounted for stress on the mooring lines and knots. The yawing of the vessels also places them in the position of taking on beam winds, which for a houseboat with questionable stability can create very unstable situations. ${ }^{14}$

\subsubsection{North Bay Village Disaster}

With Hurricane Wilma producing winds over $100 \mathrm{mph}^{15}$, it is clear why these houseboats were so vulnerable. The combined effects of the severe windage and larger than normal swells put these houseboats in an environment they were not suited or designed for, which caused the capsize of nearly 10 of these vessels.

The other major factor in the disaster was boats breaking loose from their moorings and smashing into one another, which caused large amounts of damage to both ships involved. The mooring lines and knots were unable to handle the surges and enormous forces created from the windage. Many boats broke loose as a result of this and damaged their neighboring vessels, either causing them to break free from their moorings or capsizing them.

\subsubsection{Prevention}

To prevent disasters such as this from occurring in the future, there are many things to consider. First and foremost: never underestimate Mother Nature. Hurricanes are extremely unpredictable and should be avoided at all cost, regardless of forecasted severity. They produce some of the harshest and dangerous weather, leading to massive amounts of damage, and even death. Many of the houseboat residents decided to ride out Wilma, just as they had Hurricane Katrina, which proved to be a huge mistake. The unpredicted winds from the west left them unsheltered as the storm battered their boats. John Nye died during hurricane Katrina with a similar attitude, underestimating the strength of Katrina. Nye died trying to "ride out the storm" when his houseboat capsized. ${ }^{16}$

Another key factor to consider is the owner's understanding of each individual vessel and what it is capable of handling. Many of the destroyed houseboats were flat bottomed; the owners need to understand the stability effects of this and realize they are not designed for ocean use. Several 
of the newer houseboats being constructed use a semi-catamaran hull to increase stability and sea keeping. V Hulls are also being placed at the front of houseboats to make them more maneuverable and allow them better control in rougher conditions. The latter two improvements drastically increase the survivability of a houseboat in rough conditions, making them a more suitable design for someone planning on using a houseboat on the ocean.

Many Houseboat communities are taking steps to help ensure the safety of their occupants. The city of Sausalito, CA, has set up a strict set of guidelines houseboat owners must comply with in order to live there. Rules are designed to:

- Ensure environmental sensitivity

- Govern the reconstruction, alteration, and remodeling of the houseboats

- Ensure designs are compatible with the maritime conditions of the area ${ }^{17}$

Every houseboat in the community is inspected by and approved by the building official. During this inspection the official makes sure the boat is adequate for the conditions it could encounter. The buoyancy, windage, stability, and structure are all reviewed. ${ }^{17}$

In the end, when dealing with hurricanes it is best to avoid them at all cost. Even the most advanced tracking and modeling technologies cannot predict what one of these storms will do 100 percent of the time. It seems in most major maritime disasters, people were caught off guard by these huge storms, and this will continue to happen. The only way to be truly safe is to get as far away as possible and put your life before your belongings.

\subsection{Rogue Waves}

There was little significant research on the cause of rogue waves until December $2000 .{ }^{4}$ Due to many measurements of rogue waves from onboard measuring devices on ships and oil platforms, as well as eyewitness accounts, the European Space Agency ${ }^{4}$ was convinced that rogue waves were a serious safety and economic problem. At this time, they launched the MaxWave program to confirm and study the widespread occurrence of rogue waves. A key part of the MaxWave program was the data collected by the ERS-1 and ERS-2 satellites, which surveyed the ocean surface. Both satellites would take 10 by $5 \mathrm{~km}$ "imagettes" of the sea surface every $200 \mathrm{~km}$, 30000 in total. ${ }^{4}$ The ESA takes these and mathematically analyzes them to find wave energy and direction. Within three weeks worth of images, 10 rogue waves measuring 25 meters or higher were found, a much higher number than was expected. Heller points out that one estimate from this data suggest that " 50 or more freak waves are stalking the seas right now." "Once the existence of rogue waves was established, the major focus of the research has been on determination of how they form and where they occur most often. The European Space Agency created a new research project called WaveAtlas to create an atlas of rogue waves as well as carry out statistical analysis on them. ${ }^{4}$

There is still a significant amount of debate on the subject of rogue waves, as well as ongoing research trying to solve this problem. Dysthe recognizes three main theories on the cause: 1) time-space focusing, 2) current focusing, and 3) nonlinear focusing. ${ }^{3}$ Time-space focusing basically states that faster waves overtake slower waves, and if enough waves overlap at a certain 
time the result is a rogue wave. This theory has largely been dismissed by the experts on the subject due to waves traveling in different directions, thus not being able to combine for any amount of time, as well as statistics that show the probability of this phenomenon happening is significantly lower than the current estimates on the number of rogue waves. ${ }^{3}$

Current focusing is a much more likely cause of rogue waves. Rogue waves have commonly been found where a swell or a sustained wind collides with a number of currents following a curved path (eddies) concentrated on one spot. ${ }^{19}$ Evidence from the MaxWave and WaveAtlas programs support this theory. ${ }^{4}$ The European Space Agency found problem spots where this phenomenon occurs most frequently, such as the dangerous Agulhas current off the east coast of South Africa, as well as the Gulf Stream in the North Atlantic. ${ }^{4}$ Data also shows rogue waves near weather fronts and lows.

Many scientists now agree on a third theory, nonlinear focusing. It is agreed that size and shape of rogue waves as well as frequency cannot be explained by a linear theory of superposition. Dysthe recognizes that the simplest nonlinear Schroedinger equation is a popular theory to explain freak waves. ${ }^{3}$ This theory involves a "breather," where the "breather" starts out as a weakly modulated periodic wave and eventually it develops strong focusing of energy where a small part of the wave "breathes up" at the expense of the waves around it. ${ }^{3}$ Heller points out that, "...there is no doubt whatsoever that nonlinear processes are important to water wave physics. Any breaking wave is exhibiting nonlinear behavior."18 Heller also recognizes the importance of the Schroedinger equation of quantum physics in describing the phenomenon of rogue waves, as well as the Benjamin-Feir instability, a well established nonlinear wave process. ${ }^{18}$ However, since these equations are nonlinear and are modeled after a periodic wave, which is impossible considering there are various waves and directions in most bodies of water, the ability to predict rogue waves becomes much more complicated and basically unsolvable, at least up to this point.

\subsubsection{Dangers of Rogue Waves}

While hurricanes and most recently tsunamis are often regarded as the true "killers" of the sea, this is mostly due to their effects on shore populations and structures. However, rogue waves account for hundreds of deaths at sea. Rogue waves can be very dangerous as well as lethal for inadequately designed ships and structures. Lawton points out that of the 60 super carriers lost to "sudden flooding" between 1969 and 1994, rogue waves were responsible for approximately 22, as well as 542 lives. ${ }^{20}$ These numbers only account for super carriers; including other ships and pleasure craft, these numbers would be significantly higher. ${ }^{20}$

Heller notes that the danger of rogue waves is not only a matter of the height, but also of the steepness. He states that a 40 foot wave in a sea with a significant wave height of 40 feet is far less dangerous than the same wave in a 16 feet significant wave height. ${ }^{18}$ The reason is that the 40 foot sea will have a longer mean wave length than the 16 foot sea. This results in a steeper wave which will create a greater rolling moment if the ship is hit from port or starboard or the effect of hitting a wall if the ship meets the rogue wave bow first. Also, Heller points out that steep waves tend to break, which makes the rogue waves even more dangerous due to greater forces acting on the ship and greenwater. ${ }^{18}$ 


\subsubsection{Derbyshire}

As stated earlier, rogue waves are the cause for many lives lost and ships capsized. This was the unfortunate case for the Derbyshire, a British bulk carrier, and many more ships lost at sea. On September 9, 1980, the Derbyshire was transporting iron ore concentrates to Kawasaki, Japan, but sank near Japan as the result of a rogue wave. All 44 people on board perished. For several years, the cause of the worst British commercial sea loss ever was unknown. Extensive underwater investigation showed that structural defect on the vessel was not the cause of the sinking as was once thought. ${ }^{21}$ The reason the Derbyshire sank was bow diving as a result of the rogue wave. ${ }^{21}$ Rough seas caused water to flood the tanks at the bow of the ship causing it to sit lower in the water. This made the Derbyshire unable to climb over an 80 foot rogue wave which quickly sank the ship. ${ }^{21}$

\subsubsection{Ocean Ranger}

The Ocean Ranger was a drilling rig off the coast of Newfoundland that was destroyed by a 26 meter rogue wave on February 14, 1982. All 84 people aboard the platform perished, making the event the Canada's worst tragedy at sea since World War II. ${ }^{22}$ In this tragedy, the wave tore open the ballast control room, which was only 8.5 meters above sea level, causing valves to open on their own and let water into the Ocean Ranger's pontoons. Poor training of control room personnel also led to the demise of the platform and crew, as they were unable to repair the problem. The lack of safety equipment left the crew unable to escape the sinking rig. ${ }^{22}$

\subsubsection{Norwegian Dawn}

The Norwegian Dawn is one of the largest cruise ships in the world, with a length of 965 feet, a beam of 105 feet, and a draft of 27 feet, weighing 92,259 gross tons. On April 16, 2005, the Norwegian Dawn became the latest publicized victim of a rogue wave on a routine trip from New York City to Miami, FL. While the Norwegian Dawn did not sink, it suffered damage of up to $\$ 750,000 .^{23}$ Late April 15 and early April 16, the ship was maneuvering in rough seas: 40 knot winds and 14 to 28 foot seas. To minimize the severity of the seas, the captain slowed to 7 knots and directed the ship into deeper water while steering directly into the wind and seas to minimize rolling. ${ }^{23}$ At $06: 10$ on April 16, the ship was struck by a rogue wave over the bow of the ship. ${ }^{23}$ The damage occurred to the structures at the bow of the ship. The force of the wave sheared off the welds of the aluminum rail supports on the balconies of the front two cabins, which caused the rails to break loose and crash into the cabin windows. ${ }^{23}$ The broken glass obstructed the drains which lead to large amounts of water in the two cabins and flood damage to 61 other cabins. ${ }^{23}$ Injuries were minimal, and only two passengers suffered lacerations and 10 received bruises. ${ }^{23}$ The damage to life and the ship could have been much worse, but the reduced speed the captain piloted the ship at in the rough seas limited the damage. ${ }^{23}$

\subsubsection{Prevention}

There are many dangers presented by rogue waves, some of which can be remedied by higher safety standards in ship design. For example, ships and oil platforms are designed to withstand a 
wave of 15 meters high, while rogue waves can reach up to 35 meters. Some ships are designed to be safer and better prepared for rogue waves such as military ships and cruise ships.

However, Heller points out that weaker ships, such as container ships and tankers, often break in an encounter with a rogue wave. The reason for this is that "the bow buries itself in the wall (of water), the wave breaks over the unsupported midships, snapping the vessel in two and often sinking it in a few minutes." 18 The European Space Agency estimates that one supertanker or container ship sinks every month or two as a result of rogue waves. ${ }^{4}$ A solution to this problem is to raise the standards tankers and containerships are built to meet the standards of passenger vessels such as cruise ships. PNA points out that having a greater number of passengers on the ship as well as a greater number of passengers below the margin line requires a larger degree of safety than for cargo vessels. ${ }^{37}$ Also, when waves are breaking over the bow, reducing the speed of the ship reduces the forces acting on it as shown by the Norwegian Dawn. Comparing the outcome between the Norwegian Dawn and Ocean ranger, adequate training of captain and crew also appeared to play a large factor in survivability of the structure and personnel. Design of a ship is only a way to improve chances of survivability of a rogue wave; more research needs to be done on the formation and location of rogue waves in order to avoid them altogether.

\subsection{Tsunamis: The Sinar Andalas}

On December 26, 2004, a magnitude 9.0 earthquake struck the Indian Ocean off the west coast of northern Sumatra, Indonesia; according to the United States Geological Society (USGS) the earthquake was the fourth largest recorded event in the world since 1900, and the largest since the 1964 quake in the Prince William Sound of Alaska. The upthrust occurred where the India and Burma tectonic plates met, with a vertical seafloor rise of almost five meters. ${ }^{24}$ The resulting tsunami spread quickly across the Indian Ocean, with the National Geophysical Data Center reporting small run-up occurring even as far away as the United States and South America. Much closer to the epicenter of the event, the tsunami produced run-up values ranging from two to thirty-four meters in the Banda Aceh region of Indonesia, with the highest run-up values occurring on the west coast near the city of Lhoknga. ${ }^{25}$ Run-up values of such a large magnitude would produce widespread flooding and devastation throughout the region. In the Aceh and Sumatra provinces alone, at least 108,000 people were killed and over 400,000 displaced. Estimates have shown that worldwide over 280,000 people were killed by the wave and the resulting flooding, with over a million displaced from their homes and villages. ${ }^{24}$

\subsubsection{Economic Losses}

While the overall economic and personal losses were exceedingly great, the shipping industry faced fewer losses than perhaps would be expected from such a significant event. According to the Willis Marine Reinsurance Review of February 2005, total economic losses were estimated at over ten billion dollars, the fourth most costly natural event of 2004 . While hull losses were not available at the time of the report, only about 15 million dollars of cargo were estimated to be lost at sea. ${ }^{1}$ Several ships were damaged as a result of separating from their moorings and colliding with other ships and port structures in the chaotic harbor tides, while many others were pushed inland and ran aground when the water receded. The lack of immediate hull losses as a result of capsize can probably be attributed to the fact that the ships that were out to sea or a reasonable distance from shore did not feel more than a sea swell, as the true height of a tsunami 
does not become apparent until it reaches the coastline. Another contributing factor is port design; ships in enclosed ports, whether by natural or man-made design, often faced extreme increases in tide but no major wave events.

\subsubsection{Sinar Andalas}

While two ships in the Nicobar and Andaman islands faced capsize, most likely as a result of a breach in their dry-dock facilities, the most notable capsize of the tsunami was the Sinar Andalas. The cement carrier was owned by Samudera Shipping Line Ltd, which operated the ship out of the PT Semen Andalas cement plant owned by the LaFarge group. According to a statement released by the Board of Directors of Samudera, the value of the Sinar Andalas at the time of capsize was $\$ 9.735$ million dollars, attributing to $0.69 \%$ of their revenues. ${ }^{26}$ The ship had just completed loading over 5,000 tons of cement when the wave struck, and only 4 of the 19 crew were rescued. ${ }^{27}$

Ships at the cement plant docked perpendicular to the ocean, facing a beam seas condition. When the tsunami struck, the wave washed across the beam of the ship, which would have created an extreme rolling motion. The location where the ship rested after the wave of the ship was perpendicular to the open ocean, so the ship must have faced both roll and yaw motions to come to rest at its final capsized position, as seen in Figure 2.

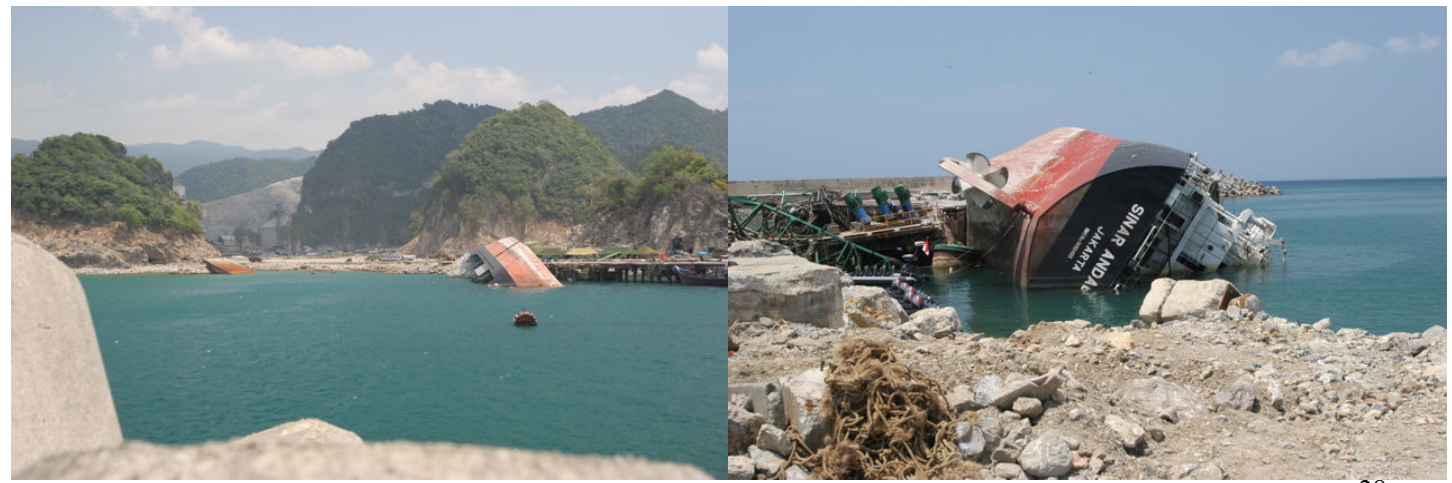

Figure 2: The Sinar Andalas capsized at the Semen Andalas cement plant ${ }^{28}$

The yawing of the ship could have been attributed to two different factors, both of which may have had an effect on the motion of the ship. Though the ship was predominantly perpendicular to the open ocean, the stern faced the sea at a slight angle, which would have allowed the wave's energy to break over the stern first. The other factor that may have contributed were the vessel's moorings; because the wave struck the stern first, the mooring lines on that end of the ship may have broken before the bow lines. In either case, the ship would have faced a yawing rotation that would have left it in its current position. Both of these were likely factors in the state of this vessel, but for the purposes of this paper only the rolling motion, which was the predominant factor in the capsize, will be analyzed.

To ascertain the initial stability of the ship, the hydrostatics of the vessel had to be determined. The Sinar Andalas was built by Watanabe Shipbuilding Co. and classed by Nippon Kaiji Kyokai, commonly known as Class NK. ${ }^{29}$ This classification society is headquartered in Tokyo and, "By 
the end of Dec. 2004, the Society had 6,290 ships over 126 million [Gross Tons] under class." ${ }^{, 30}$ Though the class of the ship had been suspended, Watanabe shipyards built two other cargo tramps with almost identical particulars the same year the Sinar Andalas was built. ${ }^{29}$ The SunYoung is one of those ships, with ship's particulars show in the following table.

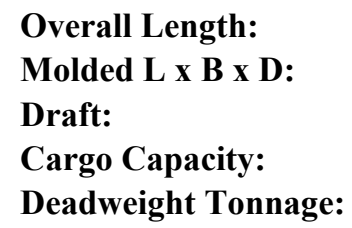

100.79 meters

$92.91 \times 17.2 \times 9.0$ meters

7.125 meters

8404 MT Bale, 9386 MT Grain 6502 MT

Table 1: SunYoung ship particulars ${ }^{31}$

Typical grain ships range from 40,000-60,000 tons, placing the Sinar Andalas among the smallest of grain carriers, and atypical of normal dry bulk/grain carrier design. ${ }^{13}$ Pictures of the ship before the capsize show a bulb typical to many cargo ships; the capsized views in Figure 3 show a fairly short parallel mid-body, which indicates a lower block coefficient (CB) than is usually attributed to container and cargo ships.

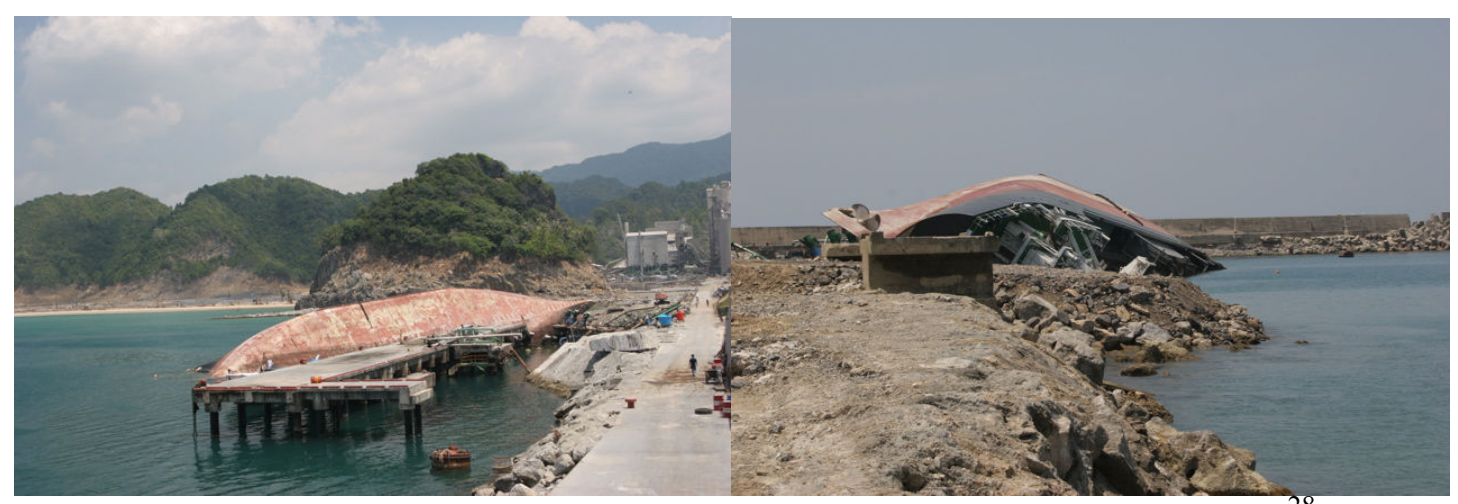

Figure 3: The Sinar Andalas capsized at Semen Andalas ${ }^{28}$

Because of the proprietary nature of the information regarding the ship, neither the shipping company nor the classification society were prepared to discuss the naval architecture of the vessel, so approximations were formed. Based on the classification numbers and pictures of the ship, an approximation of the hull was created in Fastship, a hull modeling software package created by Proteus Engineering. A basic tanker hull was utilized as a starting point then modified using the parametric subprogram Fastgen. ${ }^{32}$ Using this application, a hull was created that very accurately models both the ship particulars and hull shape of the Sinar Andalas, as seen in the graphic below. The hull created reflects the displacement of the ship though neglects the particular structures on deck, including the deckhouse, superstructures, and loading cranes. 


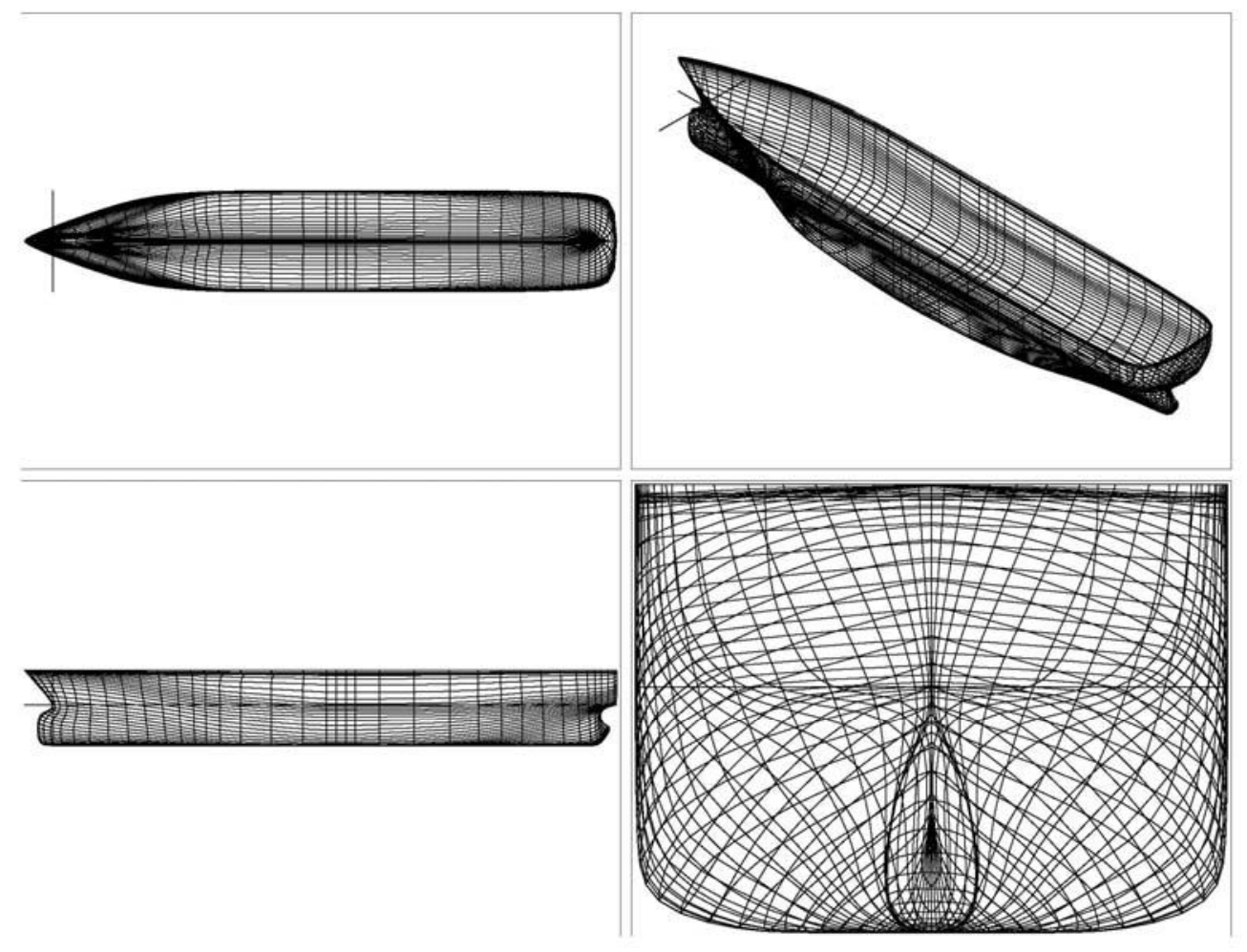

Figure 4: Sinar Andalas Hull Model

The views above show how comparable the ship created is to the actual Sinar Andalas seen in the pictures above. The hydrostatics provided by Fastship gave the following parameters for the ship:

$\begin{array}{cccc}\text { Mass } & 7,669,554 \mathrm{kgf} & \mathbf{V C B} & (-) 3.9 \mathrm{~m} \\ \text { LCG } & 48.961 \mathrm{~m} & \mathbf{C}_{\mathbf{B}} & 0.624 \\ \text { LCB } & 48.961 \mathrm{~m} & \mathbf{C}_{\mathbf{X}} & 0.962 \\ \text { Draft } & 7.125 \mathrm{~m} & \mathbf{C}_{\mathbf{P}} & 0.633 \\ \text { Length OA } & 101.06 \mathrm{~m} & \text { Area WP } & 1318.403 \mathrm{~m}^{2} \\ \text { Beam OA } & 17.2 \mathrm{~m} & \text { Depth } & 9.51 \mathrm{~m}\end{array}$

Table 2: Hydrostatic values for Sinar Andalas model hull

After these hydrostatic numbers were found by Fastship, the hull model was converted into a set of SCHP offsets and exported into the HECSALV Ship Project Editor, a program which can explore the intact stability of a ship in more depth than the Fastship program allows. It should be noted that even in HECSALV the depth was changed to reflect the actual depth of the ship, which was 9 meters. The depth plays a key role in stability calculations, given the deck immersion that can occur at large angles of heel. 


\subsubsection{Stability}

In the analysis of the houseboat in hurricane conditions, the GZ (righting arm) was measured with the formula $G Z=G M * \sin (\theta)$. While this formula works well for small angles of heel, the Sinar Andalas almost certainly faced extremely large angles of heel, perhaps up to 90 degrees, when it capsized. For stability calculations at large angles of heel, “...the buoyant force vector does not pass through the metacenter," so the above mentioned small angle formula does not apply. ${ }^{13}$ To find the GZ at very large angles, the cross curves of stability must be used, which measure various GZ values at various angles of heel. These curves are created in the HECSALV program, which uses an integration method to measure displacement vs. angle of heel. Based on these curves the following statical stability curve was produced:

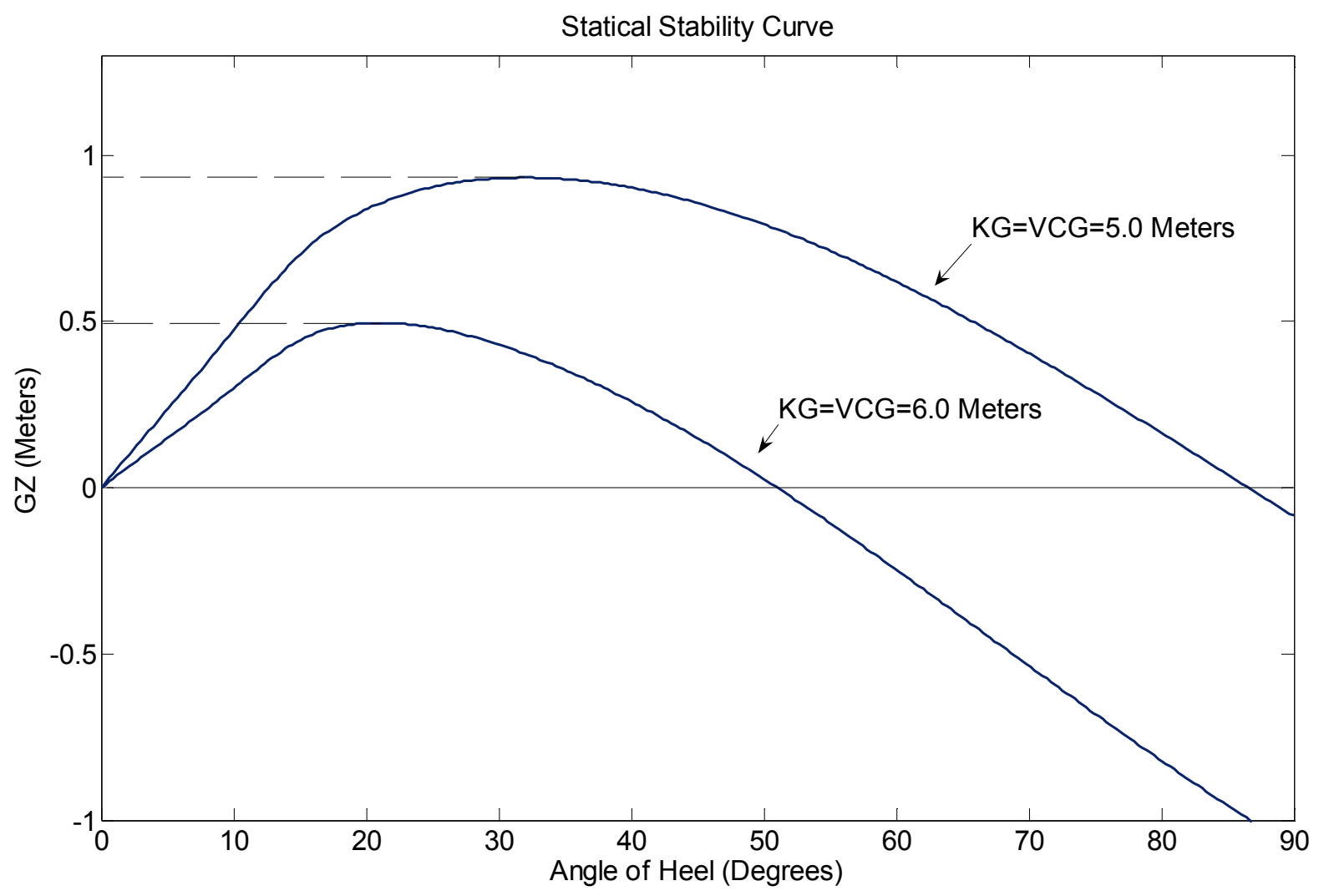

Figure 5: Statical Stability Curves for Sinar Andalas hull model

This graph is based on varying values for the vertical center of gravity, VCG, also known as KG; all of these values were measured at the design draft of 7.125 meters. The true value of the KG for the Sinar Andalas was unknown, so these numbers were estimated based on the particulars of the ship, the classification society report, and the pictures of the vessel. The maximum righting arms for both $\mathrm{KG}$ values occur between about 23 and 33 degrees, with the angle of diminishing stability decreasing with increasing KG, which is to be expected. With loading completed, the $\mathrm{KG}$ of the Sinar Andalas would probably have been in this range, if not lower, given the weight and location of the cement that was loaded. For lower KG values the GZ values become very large, with a maximum righting arm of 3.2 meters occuring at a heel angle of 60 degrees for a 
KG of 2.0 meters. The International Maritime Organization (IMO) critera for the general stability of ships, given by IMO resolutions A.469 and A.562, provide the following guidelines:

a) "The righting lever GZ should be at least 0.20 meters at an angle of heel equal to or greater than 30 degrees."

b) "The maximum righting arm should occur at an angle of heel preferably exceeding 30 degrees but not less than 25 degrees."

c) "The initial metacentric height GM that is corrected due to free surface effects should not be less than $0.15 \mathrm{~m}$." (The measured GM for the model hull is 0.6 meters.) ${ }^{31}$

The GZ curves for the model Sinar Andalas hull model apply to all of these guidelines, depending on the KG value applied. The KM value for the ship at design draft was 7.688 meters, and using the formula $\mathrm{GM}=\mathrm{KM}-\mathrm{KG}$, the metacentric height would have stayed well within limits barring any unusual loads on deck. The 5000 MT's of cement would have lowered the KG of the ship by a significant amount, possibly even lower than the 5.0-6.0 meter range seen in the graph. Even with a KG value of 6.0 meters, the ship would have to heel past 50 degrees to face a negative GZ and in turn, negative stability. Given these numbers, the ship was designed to face large angles of heel. A wave of the tsunami's magnitude would have created an incredible rolling motion, more than enough to push the ship to such large heeling angles. According to Jose Borrero, of the USC Tsunami Research Center, "The high water marks at the mooring of the Sinar Andalas were over 31 [meters]. One eyewitness I talked to in the area said it was like a wall of water coming in from the ocean that spanned the entire horizon." 28 This wave height is consistent with the wave heights reported by the NGDC, though it ranks among the highest waves reported. This wave may have rolled the ship past a heel angle of 90 degrees, which would not only have pushed the ship well past its range of stability but would also have created downflooding if the cargo hatches were open when the wave arrived. The flooding would have reduced the active buoyancy and the ship stability in turn.

\subsubsection{Prevention}

Though ship design could not overcome the power of a wave topping 30 meters, port design can play a major factor in reducing the shipping losses from a tsunami. In the port of Chennai, on the Indian coast, ships in the harbor faced rapid increases in tides rather than a true wave. Raja Simhan, of The Hindu Business Line writes, "According to an eyewitness, it all happened in less than an hour. A small ship swirled several times, before hitting a large ship and was dragged out of the harbour. Of the three ships involved in the collision, Gem of Tuticorin, loading sugar, sustained heavy damage; it is estimated that about 1,500 tonnes of raw sugar was in the hatch. The other vessels were $A B G$ Kesava and Canadian Express. ABG-Kesava hit two hoppers on the wharf and damaged them. It also hit the wharf cranes and damaged the equipment. Gem of Tuticorin was damaged by the impact of $A B G$-Kesava." 33 The damage done by these ships was caused solely by tide fluctuation; the buoyant forces heaved the ships from their moorings, leaving them free to travel in eddies created in the harbor by the tidal forces. Port Blair, of the Andaman Islands, also faced a very similar situation. When the earthquake struck, the ships in the harbor were instructed to leave for sea immediately. Fifty minutes later, the first wave in a series of four struck the harbor, the largest being 5 meters in height; it was reported that the harbor faced a drastic increase in tide, up to 2 meters in some cases. ${ }^{34}$ Either the small waves or 
the increases in tides caused two ships, the MV Teal and the Andaman Rani, to capsize in drydock. $^{35}$ The toll would almost certainly have been higher had port officials not ordered the port to be evacuated when the first earthquakes were felt.

An analysis of the port design can give some insight into why these two ports faced rapid tide increases and small waves rather than the force of one large wave that the Sinar Andalas faced. Figure 6 shows pictures of the three ports, with Port Blair on the bottom left, the Semen Andalas harbor on the upper left, and Chennai on the right:

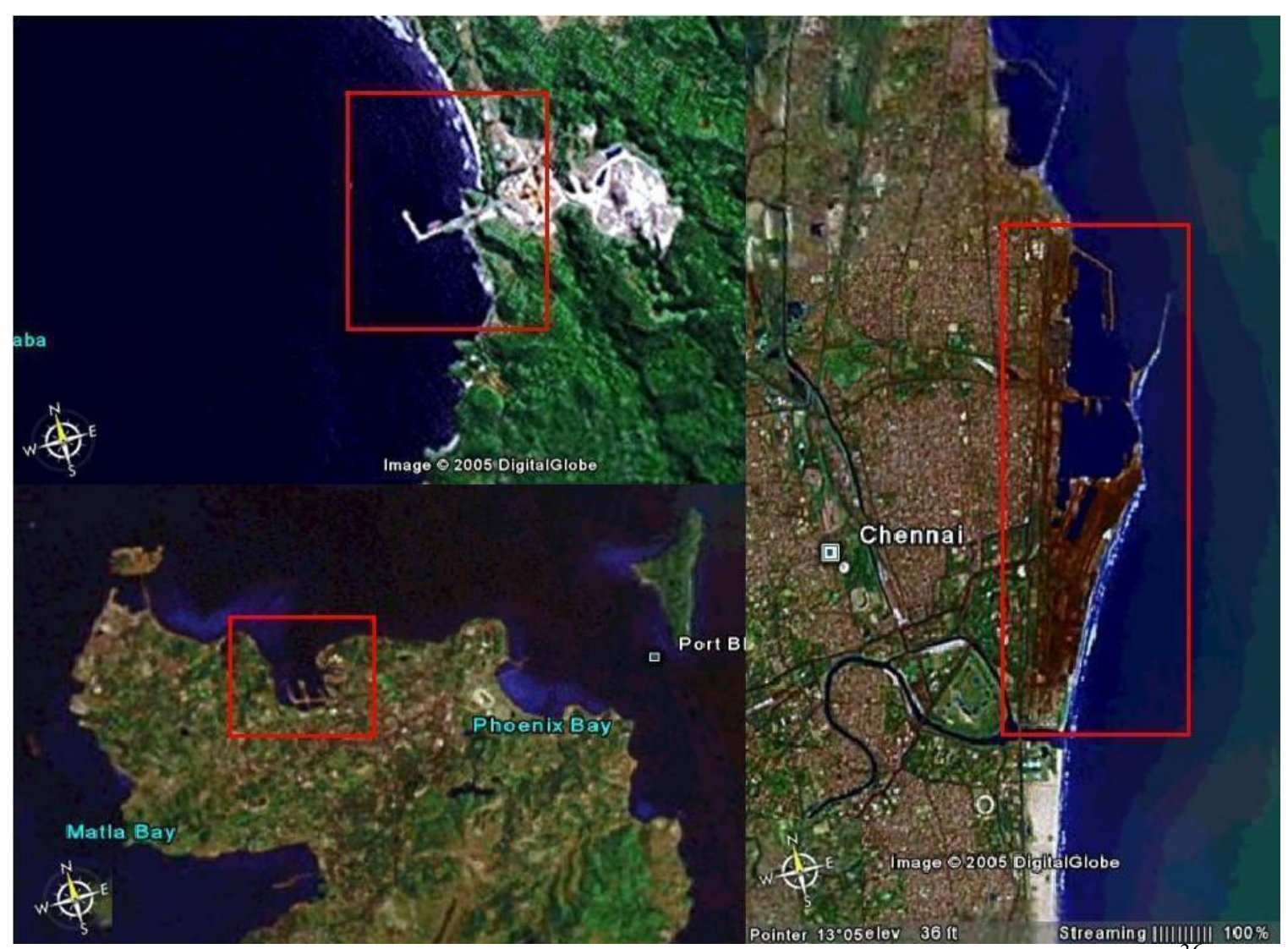

Figure 6: Semen Andalas, Chennai, and Port Blair (Clockwise from top left) ${ }^{36}$

The harbors in the graphic are marked in red, and one noticeable difference stands out between Port Blair and Chennai and the harbor at Semen Andalas: the enclosure. Chennai harbor has a man-made breakwater that encloses the harbor and protects the docked ships from the sea, while the harbor at Port Blair is a naturally occurring bay that does not face directly into the open sea. Comparatively the harbor at the Semen Andalas cement plant has no protection; it faces the sea and offers nothing to blunt the power of a large tsunami wave. This type of port design seems very ill-suited for an area that faces a risk of tsunami, and was the major factor in the Sinar Andalas facing a 34 meter wave rather than a series of small waves or a large increase in tide.

The earthquake and resulting tsunami of December 2004 was an extraordinary natural disaster that could not have been predicted. From the capsize of the Sinar Andalas much can be learned about protection from these devastating waves. Ports in tsunami-threatened areas need to be enclosed and protected from the full brunt of the wave, a measure which would surely spare both 
lives and ships. In addition, ships need to evacuate the harbor as soon as an earthquake is felt, to get to open water. Many lives were saved in Port Blair by the timely evacuation of the harbor and similar protocols need to be adopted in other harbors that face the tsunami threat. While devastating, what can be learned from one disaster can be turned into knowledge to save lives in the future.

\subsection{Pedagogical Benefits}

From pop culture references such as Gordon Lightfoot's song "The Wreck of the Edmund Fitzgerald" and major motion pictures including Titanic and The Perfect Storm to media coverage of oil tankers running aground, fast ferries capsizing, and cruise ships subjected to rogue waves, students from nearly all backgrounds enter their course work already introduced, knowingly, or unknowingly, to ship instabilities. By capitalizing on this exposure, ocean engineering educators have an early advantage in the quest to excite students about the subject and research. The conduct of formal case studies, such as those presented herein, or informal case studies given as individual, group, or instructor presentations, not only enliven class discussions, but help fulfill multiple ABET criteria.

As an example, over the course of a one semester Ship Dynamics course, each individual student was required to present a five minute discussion of a news story, accident report, or historical record of some incident related, in some way, to vessel dynamics. Each lecture began with one of these five-minute student presentations. Students discussed everything from re-creations of historical vessels, to piracy off Somalia, to survivability in hurricanes, to landing helicopters on moving ship decks, to the class-favorite, a party barge that capsized when all passengers ran to one side to gawk at bathers on a nude beach. This activity requires little class time yet reinforces ABET criteria that "students attain:

(f) an understanding of professional and ethical responsibility

(g) an ability to communicate effectively

(h) the broad education necessary to understand the impact of engineering solutions in a global, economic, environmental, and societal context

(j) a knowledge of contemporary issues"38

Specifically, objectives (f) and (j) are often difficult to measure within the traditional curriculum. Thus each examination in the class included a short answer question requiring the students to identify some set number of current issues related to ship dynamics and to briefly discuss ethical, design, regulatory, or operator considerations relevant to the issue, thus yielding a quantifiable measure of students' absorption and retention of the current events and ethical considerations discussed over the course of the semester. In end of term student course evaluations, numerous individuals specifically listed the in-class presentations as a positive aspect of the class, while no student named them as a negative.

It is quite feasible to formalize this through assignment of written case studies, such as those presented in Section 2.0 of this work. Written case studies can be incorporated through an independent study component of the curriculum and/or a designated special topics course on current events in the maritime community. Assuming faculty availability, a technical elective special topics course, focusing upon current events and the resultant ethical considerations, in 
which the primary student deliverable is a case study, or series of case studies, could serve as a culminating educational experience for the above listed ABET criteria as well as showing that "students attain:

(a) an ability to apply knowledge of mathematics, science, and engineering

(e) an ability to identify, formulate, and solve engineering problems

(i) a recognition of the need for, and an ability to engage in life-long learning

(k) an ability to use the techniques, skills, and modern engineering tools necessary for engineering practice." 38

As described by Brent and Felder, the benefits of written work, in this particular case formally preparing written case studies, are numerous, including assisting students in drawing upon prior knowledge and identifying shortcomings in core comprehension, infusing the relevance of the subject, connecting knowledge from different parts of the core curriculum, improving critical thinking, and fostering creativity ${ }^{39}$. One might also contend that the sort of open-ended problem faced by case studies, when introduced at the undergraduate level, can aid in the transition to Perry's levels of multiplicity. That is, fostering students' recognition that engineering need not be dualistic 'right' versus 'wrong,' but that multiple 'right' answers may exist and/or that there is no known answer at all. ${ }^{40}$

\subsection{Conclusions}

The knowledge gleaned from the analysis of these disasters can be used to prepare for the future. Even with the best tools of weather forecasting, natural disasters such as the ones presented here cannot be predicted accurately one-hundred percent of the time. While the best strategy to reduce the losses attributed to these disasters is to avoid them altogether, often times warning does not come soon enough and other contingencies must be considered. Higher standards in ship design and safety criteria stand at the forefront, given that all of these disasters cause highmagnitude waves that would push the limits of any ship at sea. In the case of hurricanes and tsunamis, better planning regarding port design and procedure must be applied. Hurricanes will almost always provide a window of opportunity to leave the area, and the often an earthquake will predate the coming tsunami. In both cases those ships in port must know what to do, whether that decision is to depart for sea or to take the crew and travel inland; each case, just like each disaster that precedes it, will be unique. In the end, for any disaster at sea, a well designed ship combined with informed decisions and careful contingency plans might be the difference between the loss of a crew, a ship, or a cargo, and their safety. Simultaneously, this paper demonstrates the feasibility and benefit of incorporating case studies in the ocean and marine engineering academic curriculum.

\section{Acknowledgements}

Thanks to Jose Borrero for providing numerous pictures of the Sinar Andalas from his trip to Indonesia; without these pictures the hull modeling process would have become much more difficult. Thanks are also due to Martin Eskijian, of the California State Lands Commission, for his correspondence regarding the destruction in the Andaman and Nicobar Islands. 


\section{References}

1. "Willis Reinsurance Review.” IUMI.com 2005. International Union of Marine Insurance. 12 December 2005. $<$ http://www.iumi.com/pdf/Willis\%20Marine\%20RI\%20Review\%20Feb\%2005.pdf $>$.

2. “The Greatest Storm on Earth.” 15 Oct. 2001. 24 Dec. $2005<$ http://starryskies.com/articles/dln/895/hurrican.html>.

3. Dysthe, Kristina B., Harald E. Krogstad, Herve Socquet-Juglard, and Karsten Trulsen. "Freak Waves, Rogue Waves, Extreme Waves and Ocean Wave Climate.” 10 June, 2003.

$<$ http://www.math.uio.no/ karstent/waves/index_en.html $>$.

4. "Ship-Sinking Monster Waves Revealed by ESA Satellites.” European Space Agency. 21 July 2004.

$<$ http://www.esa.int/esaCP/SEMOKQL26WD_index_0.html >.

5. Cramer, M.S. "Water Waves.” FluidMech.net. 2004. <http://www.fluidmech.net/tutorials/ocean/tsunami.htm>.

6. Tenenbaum, David. "Lessons of the Edmund Fitzgerald.” WhyFiles.org. 2000. The Why Files.

$<$ http://whyfiles.org/shorties/067shipwreck/index.html $>$.

7. Wikipedia.org. 2005. Wikimedia Foundation, Inc. $<$ http://en.wikipedia.org $>$.

8. SSEFO.com. 2005. S.S. Edmund Fitzgerald Online. <www.ssefo.com>.

9. CIMSS. 2005. Cooperative Institute for Meteorological Satellite Studies. $<$ http://cimss.ssec.wisc.edu/>.

10. Driscoll, Amy. "Storms dealt hard blow to houseboat living." MiamiHerald.com. 17 Nov. 2005. 24 Dec. 2005 $<$ http://www.miami.com/mld/miamiherald/news/weather/hurricanes/13187476.htm?source=rss\&channel=miamiher ald_hurricanes>.

11. "Storm damage varies by community." MiamiHerald.com. 30 Oct. 2005. 24 Dec.2005

$<$ http://www.miami.com/mld/miamiherald/13026740.htm>.

12. Ovalle, David. "North Bay Village houseboat community dejected after major losses."MiamiHearld.com. 24 Oct. 2005. 24 Dec. 2005-12-27

$<$ http://blogs.herald.com/herald_hurricane_reports/2005/10/north_bay_villa_1.html $>$.

13. Zubaly, Robert. Applied Naval Architecture. Centreville: Cornell Maritime Press, 1996.

14. "Dulhunty.com." Windage and Velocity. 10 July 2005. 24 Dec. $2005<$ http://www.dulhunty.com/dmp2.htm>.

15. National Oceanic and Atmospheric Administration. 24 Dec. $2005<\mathrm{http} / / /$ www.weather.gov/storms/wilma>

16. Dolan, Jack. "Katrina plucks 7 from disparate backgrounds." MiamiHerald.com 27 Aug. 2005. 24 Dec. 2005

$<$ http://www.miami.com/mld/miamiherald/12493718.htm>.

17. "Specific Use Requirements." City of Sausalito 24 Dec. 2005

$<$ http://www.ci.sausalito.ca.us//business/cdd/zoningord/July\%2015\%20Draft/ChapTen44\%20PC\%202003.07.15\%2

$0 \mathrm{db} . \mathrm{pdf}>$. 
18. Heller, Eric J. "Freak Waves: Just Bad Luck, or Avoidable?” Europhysics News. Sept-Oct 2005. $<$ http://www.europhysicsnews.com/full/35/article4.pdf $>$.

19. "Rogue Waves.” EnviroLiteracy.org. 2002. Environmental Literacy Council.

$<$ http://www.enviroliteracy.org/article.php/257.html >.

20. Lawton, Graham. “Monsters of the Deep.” New Scientist Magazine. Vol 170, Iss. 2297. 30 June, 2001, pp 28-32.

21. "Derbyshire Sinking Inquiry Reopens." 12 March, 1998. British Broadcasting Corporation.

$<$ http://news.bbc.co.uk/1/hi/uk/64828.stm>.

22. "The Ocean Ranger Disaster." Canadian Broadcasting Corporation. < <http://archives.cbc.ca/IDD-1-70-

349/disasters_tragedies_extreme_weather/ocean_ranger/>.

23. "Marine Accident Brief." National Transportation Safety Board. 30 Nov. 2005. Accident No. DCA-05-MM-

018. <http://www.ntsb.gov/publictn/2005/MAB0503.pdf>.

24. "Magnitude 9.0 - SUMATRA-ANDAMAN ISLANDS EARTHQUAKE." USGS Earthquake Hazards Program. 2004. United States Geological Society. 15 December 2005.

$<$ http://earthquake.usgs.gov/eqinthenews2004/usslav/>.

25. “Tsunami Runup Database.” National Geophysical Data Center. 2005. NOAA Satellite and Information Service. 15 December 2005. <http://www.ngdc.noaa.gov/seg/hazard/tsrnsrch_idb.shtml>.

26. "Sinar Andalas capsized by tidal wave in Aceh." Listedcompany.com. 2004. Samudera Shipping Line Ltd. 15 December 2005.

$<$ http://www.listedcompany.com/ir/samudera/newsroom/Sinar_Andalas_capsized_by_tidal_wave.pdf $>$.

27. “Titan mobilizes for SINAR ANDALAS removal.” MarineLog.com. 2005. Marine Log. 12 December 2005. $<\mathrm{http}: / /$ www.marinelog.com/DOCS/NEWSMMV/2005jul0132.html $>$.

28. Borrero, Jose. "Re: Research on tsunami shipping damages.” E-mail to the author. 10 Oct. 2005.

29. “SIN 2005: Shipping Intelligence Network.” Clarksons.net. 2005. Clarkson PLC Group. 6 Dec. 2005.

$<\mathrm{http}: / /$ www.clarksons.net>.

30. ClassNK.or.jp. 2005. Nippon Kaiji Kyokai(ClassNK). 6 Dec. $2005<$ http://www.classnk.or.jp>.

31. KRS.co.kr. 2005. Korean Register 6 Dec. $2005<$ www.krs.co.kr>.

32. Fastship 6. 2002. Proteus Engineering. <http://www.proteusengineering.com>.

33. Simhan, Raja. "Tsunami: Chennai Port escapes major damage.” The Hindu Business Line. 2005. The Hindu Group. 2 Jan. $2006<$ http://www.thehindubusinessline.com>.

34. "Ports: The Port at Port Blair, South Andaman Islands." ASCE.org. 2005. American Society of Civil Engineers. 2 Jan. $2006<$ http://www.asce.org/files/pdf/tsunami/3-7.pdf $>$.

35. "Tsunami training helped save lives, but little else.” WebIndia123.com. 2005. Suni Systems (P) Ltd. 2 Jan. 2006 $<$ http://news.webindia123.com/news/showdetails.asp?id=59431\&cat=World $>$.

36. GoogleEarthBeta. 2005. Google. <http://earth.google.com>. 
37. Lewis, Edward V, Ed. Principles of Naval Architecture- Volume 1: Stability and Strength. Jersey City: The Society of Naval Architects and Marine Engineers, 1988.

38. ABET Engineering Accreditation Commission. Criteria for accrediting engineering programs. Baltimore, MD, 2006

39. Brent, Rebecca and Felder, Richard M., "Writing Assignments-Pathways to connections, clarity, creativity," College Teaching, 40(2), pp. 43-47, 1992.

40. Wankat, Phillip C. and Oreovicz, Frank S. Teaching Engineering, reprinted online by Purdue University, $<$ https://engineering.purdue.edu/ChE/News_and_Events/Publications/teaching_engineering/index.html $>$ 